\title{
Avaliação da atividade repelente do timol, mentol, salicilato de metila e ácido salicilico sobre larvas de Boophilus microplus (Canestrini, 1887) (Acari: Ixodidae)
}

[Evaluation of repellent activity of thymol, menthol, methyl salicylate and salicylic acid on Boophilus microplus larvae (Canestrini, 1887) (Acari: Ixodidae)]

\author{
A.M.S. Novelino ${ }^{1,3}$, E. Daemon ${ }^{1 *}$, G.L.G. Soares ${ }^{2}$ \\ ${ }^{1}$ Universidade Federal de Juiz de Fora \\ 36036-330 - Juiz de Fora, MG \\ ${ }^{2}$ Universidade Federal do Rio Grande do Sul - Porto Alegre, RS \\ ${ }^{3}$ Bolsista do $\mathrm{CNPq}$
}

\begin{abstract}
RESUMO
Verificou-se a atividade repelente do timol, mentol, ácido salicílico e salicilato de metila sobre larvas de Boophilus microplus. Essas substâncias foram usadas em emulsões em dimetilsulfuxido aquoso a 1\% ou solução aquosa. Para cada substância foram testadas três concentrações, $1,0 \% ; 0,5 \%$ e $0,25 \%$, com cinco repetições cada. Cerca de 100 larvas, com 21 dias de idade, foram inseridas na base de hastes de madeira para avaliação da repelência, a cada duas horas, totalizando 12 horas. As concentrações mais elevadas apontaram que as quatro substâncias causaram alteração no comportamento das larvas. Timol, com mortalidade de $65 \%$ e $35 \%$ de repelência e mentol e salicilato de metila, ambos com $80 \%$ de repelência foram os mais eficientes.
\end{abstract}

Palavras-chave: Boophilus microplus, repelência, substâncias naturais

\begin{abstract}
The repellent activity of thymol, menthol, salicylic acid and methyl salicylate on Boophilus microplus larvae was studied. These substances were tested according to their solubility: emulsions in 1\% aqueous dimethylsulphoxide or in pure water. Three concentrations were tested for each substance, 1.0\%, 0.5\% and $0.25 \%$, with five repetitions for each. Approximately 100 larvae at 21 days of age were placed on the base of wooden sticks and then observed for repellent action every two hours, during twelve hours. The results obtained from the higher concentrations showed that the four substances caused alterations on the larvae behavior. However, thymol (65\% of mortality and 35\% of repellency), menthol (80\% of repellency) and methyl salicylate (80\% of repellency) were the most efficient.
\end{abstract}

Keywords: Boophilus microplus, repelency, natural substances

\section{INTRODUÇÃO}

O carrapato Boophilus microplus é responsável por causar diversos danos econômicos (Horn e Arteche, 1985), o que se reflete em perdas na produção de leite e carne (Sutherst et al., 1983), seguido de danos causados no couro devido às reações inflamatórias nos locais de fixação do carrapato (Seifert et al., 1968). Além desses fatores, o carrapato pode atuar como vetor de patógenos, tais como agentes etiológicos da tristeza parasitária bovina (Gonçalves et al., 1999).

Diversas plantas, denominadas aromáticas, possuem em sua constituição óleos essenciais, que são compostos voláteis formados por uma mistura complexa de metabólitos naturais, dentre os quais se destacam os monoterpenóides e arilpropanóides (Bessiere et al., 1994; Jantan et

Recebido em 26 de julho de 2006

Aceito em 10 de abril de 2007

* Autor para correspondência (corresponding author)

E-mail: erik@acessa.com 
al., 1994; Martins et al., 1998). Os monoterpenóides e arilpropanóides têm sido fontes de pesticidas de origem vegetal (Sing e Upadhayay, 1993) e, de acordo com Singh e Singh (1991), Shaaya et al. (1997) e Huang et al. (1997), muitos deles são notáveis pelas propriedades inseticidas.

O éster do ácido salicílico, o salicilato de metila, é outra substância de ampla ocorrência nos vegetais, ao contrário do ácido salicílico (Jayasekara et al., 2002). Segundo Lindberg et al. (2000), esse mesmo óleo essencial apresentou potencial acaricida no controle de Varroa jacobsoni.

Este trabalho teve o objetivo de estudar a atividade repelente de dois monoterpenóides, timol e mentol, e dois derivados de ácidos benzóicos, ácido salicílico e salicilato de metila, sobre larvas de $B$. microplus.

\section{MATERIAL E MÉTODOS}

Foram utilizadas larvas de B. microplus com cerca de 21 dias de idade, obtidas de posturas advindas de fêmeas estabelecidas na colônia da Embrapa Gado de Leite em Coronel Pacheco, Minas Gerais. As larvas foram distribuídas em quatro grupos com cinco repetições cada: um controle e três tratados, por produto testado. Recipientes de polietileno com $4 \mathrm{~cm}$ de altura e $5 \mathrm{~cm}$ de diâmetro foram preenchidos com areia lavada até a borda e dispostos em grupos de cinco em bandejas plásticas contendo água. Em seguida, as hastes de madeira, medindo $12 \mathrm{~cm}$ de comprimento, $0,5 \mathrm{~cm}$ de largura e $0,1 \mathrm{~cm}$ de espessura, foram imersas por 10 minutos nas emulsões e/ou soluções aquosas das substâncias testadas. Por terem baixa solubilidade em água, os dois monoterpenóides (timol, e mentol) e o salicilato de metila foram emulsificados, sob aquecimento $\left(60^{\circ} \mathrm{C}\right)$ em dimetilsulfoxido aquoso (DMSO 1\%). O ácido salicílico foi solubilizado em água. Cada substância foi testada nas concentrações de $0,25 \%, 0,5 \%$ e $1,0 \%$, com cinco repetições cada.

Após o tratamento, hastes de madeira foram fixadas no centro dos recipientes de polietileno contendo areia lavada no seu interior. Aproximadamente 100 larvas foram postas na base das hastes. Os grupos-controle, postos em copos contendo hastes embebidas apenas com o veículo - água destilada acrescida de DMSO aquoso $1 \%$-, foram mantidos em um laboratório separado dos tratados devido à elevada volatilidade de dois dos produtos testados, timol e mentol.

O comportamento dos grupos-controle e tratados foi observado e registrado de duas em duas horas durante 12 horas de observações. Considerou-se como critério de avaliação do grau de repelência a migração das larvas nas hastes de madeira e sua dispersão pelos recipientes. As hastes foram dividas em quatro seções: base, primeiro terço (base- $4 \mathrm{~cm})$, segundo terço $(4-8 \mathrm{~cm})$ e terceiro terço $(8-12 \mathrm{~cm})$. O estabelecimento desses critérios pelos autores deveu-se ao fato de que o comportamento normal das larvas de $B$. microplus é a ascensão vertical, havendo pouca ocorrência de migração lateral.

\section{RESULTADOS}

Constatou-se que, com timol a $0,25 \%$, ocorreu fuga das larvas de $B$. microplus imediatamente após a inserção das mesmas na base das hastes, com migração de quase $80 \%$ das larvas para a borda dos recipientes desde a primeira observação. Cerca de $20 \%$ das larvas migraram entre a base e o primeiro terço das hastes, sendo que todas estavam mortas já na primeira observação.

No teste com timol a $0,50 \%$ ocorreu paralisação, seguido de morte, de cerca de $55 \%$ das larvas que se encontravam na base das hastes, e entre as sobreviventes, mais de $40 \%$ migraram para a borda dos recipientes ao longo das observações. No primeiro terço das hastes, menos de $5 \%$ das larvas encontravam-se mortas, quando da primeira observação.

Com relação ao teste com timol a $1 \%$, cerca de $45 \%$ das larvas permaneceram agregadas na base das hastes e $20 \%$ no primeiro terço, tendo sido verificada a morte de larvas em ambos os grupos já na primeira observação. Os $35 \%$ restantes migraram para a borda dos recipientes, e lá permaneceram até o final das observações.

No teste com mentol a $0,25 \%$, constatou-se que mais de $30 \%$ das larvas se encontrava na base das hastes, e ao final das observações elas não 
foram observadas nessa seção. No segundo e terceiro terços das hastes tratadas, essa porcentagem variou entre $4 \%$ e $16 \%$, respectivamente, e não ultrapassou $1 \%$ ao final das observações. No primeiro terço das hastes, a porcentagem de larvas não chegou a $10 \%$, ao final das observações. Em média, $48 \%$ das larvas migraram para a borda e $42 \%$ para a lateral externa dos recipientes, caracterizando que cerca de $20 \%$ delas realizaram migração vertical e, posteriormente, foram repelidas pela substância.

No teste com mentol a $0,5 \%$, quase $40 \%$ das larvas permaneceram na base das hastes durante a primeira observação. No entanto, ao final das observações não foi verificada sua presença nessa seção. No primeiro e segundo terços essa porcentagem foi de $2 \%$ e, no terceiro terço, em torno de $30 \%$ ao final das observações. Aproximadamente $32 \%$ das larvas migraram para a borda e cerca de $36 \%$ migraram para a lateral externa dos recipientes.

No teste com mentol a $1 \%$, mais de $55 \%$ das larvas estavam presentes na base da haste, e ao final das observações constatou-se a ausência delas nessa seção. Não foram constatadas larvas no primeiro terço e, no segundo, essa porcentagem foi de $2 \%$ ao final das observações. No terceiro terço, essa porcentagem foi de $18 \%$ ao final das observações, sendo que $40 \%$ das larvas migraram para a borda e $40 \%$ para a lateral externa dos recipientes.

No teste com ácido salicílico a $0,25 \%$ e $0,5 \%$, verificaram-se resultados semelhantes aos do grupo-controle, ou seja, ao final das observações cerca de $70 \%$ das larvas encontravam-se no terceiro terço das hastes, situação considerada normal para a espécie. Na concentração a $1 \%$, cerca de $45 \%$ das larvas encontravam-se na base, no início das observações e, ao final, elas não foram observadas nessa seção. Em média, 10\% das larvas encontravam-se no primeiro e segundo terços ao final das observações, e pelo menos $50 \%$ delas migraram para o terceiro terço até ao final das observações. Ocorreu migração de $35 \%$ das larvas para a borda e cerca de 5\% delas migraram para a lateral externa dos recipientes.

No teste com salicilato de metila a $0,25 \%$, quase $90 \%$ das larvas permaneceram na base no inicio da observação e essa porcentagem chegou a $5 \%$ ao final das observações. No primeiro e segundo terços essa porcentagem variou entre 1 a $5 \%$, ao final das observações, e aproximadamente $25 \%$ das larvas migraram para o terceiro terço. Em torno de $65 \%$ delas migraram para a borda e até $1 \%$ migrou para a lateral externa dos recipientes, ao final das observações. Resultados similares foram observados na concentração de $0,5 \%$. Entretanto, na concentração a $1 \%$, o efeito repelente foi mais acentuado, pois cerca de $80 \%$ das larvas encontravam-se na borda dos recipientes, contrastando com $10 \%$ no terceiro terço e $10 \%$ distribuído nas seções restantes.

Para os grupos-controle de todos os testes, foi observado o padrão de migração esperado para a espécie, ou seja, foi crescente, ao longo das observações, para o terço superior das hastes, correspondendo, ao final, a cerca de $70 \%$ das larvas. As restantes encontravam-se distribuídas pelos primeiro e segundo terços $(15 \%)$ e a borda dos recipientes $(15 \%)$.

\section{DISCUSSÃO}

Das quatro substâncias testadas, o timol foi o único a apresentar duas ações concomitantes: repelência e mortalidade das larvas. Esse último resultado já era parcialmente esperado, pois, quando da realização de testes de avaliação de sua capacidade larvicida, ficou demonstrada sua ação letal de até $100 \%$. Os resultados referentes à repelência assemelham-se aos verificados por Tunc e Erler (2003), que constataram elevada atividade repelente do timol contra Tribolium confusum (Coleoptera: Tenebrionidae). Essa alteração comportamental foi observada já na menor concentração desse monoterpeno fenólico, verificando-se que nas concentrações maiores o efeito repelente foi sinérgico com a mortalidade provocada pela substância. A elevada atividade repelente verificada na concentração mais baixa do timol sobre B. microplus corrobora os resultados obtidos por Choi et al. (2002) e Traboulsi et al. (2002), que verificaram que o óleo essencial do tomilho, que tem como o principal componente o timol, foi responsável por causar elevada repelência sobre Cules pipiens palens (Díptera: Culicidae).

O mentol também inibiu o comportamento de subida característico das larvas de B. microplus certificado pelo deslocamento das larvas para a borda e a lateral externa dos recipientes. Esse comportamento foi observado já na menor 
concentração, verificando-se que, nas dosagens mais elevadas, essa repelência foi aumentada. A constatação de que $20 \%$ das larvas realizaram migração vertical para, posteriormente, serem repelidas, necessita de estudos mais aprofundados para que possam ser traçadas hipóteses para explicar o fenômeno. Não foram encontrados na literatura trabalhos referentes à atividade repelente do mentol sobre larvas de $B$. microplus. Veríssimo e Piglione (1998), verificaram que larvas de carrapato $B$. microplus apresentaram alteração comportamental diante da emulsão de citronela, que é também um constituinte de óleo essencial. Os autores concluíram que essa substância pode ser considerada repelente para a espécie.

Com relação ao salicilato de metila - éster metílico do ácido 6-hidroxibenzóico - derivado fenólico volátil produzido por várias espécies vegetais, cuja produção tem sido associada ao fenômeno de resistência induzida a fitopatógenos em plantas (Seskar et al., 1998), verificou-se que essa substância também apresentou elevado efeito repelente para larvas de B. microplus. Essa repelência foi acima de $80 \%$. De acordo com Maranga et al. (2003), na formulação de um feromônio sintético de atração-agregação-fixação para A. variegatum encontra-se o salicilato de metila e, de acordo com Schoni et al. (1984), o salicilato de metila sozinho, testado sobre $A$. variegatum, não provocou nenhuma alteração comportamental sobre a espécie. Nesse mesmo trabalho, cita-se a mistura do $\sigma$ nitrofenol com salicilato de metila e ácido pelargônico, uma vez que, para a ocorrência dessa atividade feromonial, é necessária a mistura desses três componentes. Essa mistura de substâncias sintéticas é comparada ao feromônio produzido pelo macho dessa espécie de carrapato, que possui essas substâncias na sua composição. Apesar de esses estudos demonstrarem atividade atraente do salicilato de metila sobre as espécies citadas, isso não foi observado no teste realizado com B. microplus, pois ocorreu o inverso, uma vez que as hastes de madeira tratadas com essa substância provocaram clara inibição do comportamento de ascensão vertical dessa espécie de carrapato. Além disso, foi estimulado um comportamento de fuga, uma vez que as larvas mostraram forte tendência de deslocamento para a borda do recipiente, comportamento observado em menor proporção quando o grupo-controle foi o observado.
O ácido salicílico ou 2-hydroxybenzoico acido, $\mathrm{C}_{6} \mathrm{H}_{4}(\mathrm{OH}) \mathrm{CO}_{2} \mathrm{H}$, é um ácido orgânico carboxílico sem cor, cristalino e solúvel em água e com freqüência utilizado na medicina como antiinflamatório e antitérmico. Segundo Stuart et al. (2000), essa substância e seus derivados sintéticos possuem efeito fagoinibidor sobre Culicoides impuctatus (Díptera: Cerapogonidae).

No presente trabalho foi verificado que o ácido salicilico, na concentração mais elevada, causou repelência em até $40 \%$, mas essa repelência não foi expressiva quando comparada à causada pelos demais produtos.

Duas das substâncias testadas que possuem elevada volatilidade, o mentol e o salicilato de metila, apresentaram alta repelência nas diferentes concentrações (dose-dependente). O ácido salicílico também apresentou efeito repelente para as larvas de $B$. microplus, no entanto, esse efeito não foi expressivo quando comparado às demais substâncias. Dessa forma, sugere-se que o mentol e o salicilato de metila possam ser substâncias promissoras na elaboração de produtos repelentes. O mesmo pode ser dito sobre o timol que, além do efeito repelente, apresentou efeito tóxico sobre larvas de B. microplus, sendo seu uso comercial uma possibilidade a ser investigada.

\section{REFERÊNCIAS BIBLIOGRÁFICAS}

BESSIERE, J.M.; MENUT, C.; LAMATY G. Variations in the volatile constituents of Peperomia rotundifolia Schlecht. \& Cham. Grown on different host-trees in Guadeloupe. Flav. Frag. J., v.9, p.31-133, 1994.

CHOI, W.S.; PARK, B.S.; KU, S.K. et al. Repellent activities of essential oils and monoterpenes against Culex pipiens pallens. $J$. Am. Mosq. Control Assoc., v.18, p.348-351, 2002.

GONÇALVES, P.M.; PASSOS, L.M.F.; RIBEIRO, M.F.B. Detection of IgM antibodies against Babesia bovis in cattle. Vet. Parasitol., v.82, p.11-17, 1999.

HORN, S.C.; ARTECHE C.C.P. Situação parasitária da pecuária no Brasil. Hora Vet., v.23, p.12-32, 1985. 
HUANG, Y.; TAN, J.M.W.L.; KINI, R.M. et al. Toxid and antifeedant action of nutmeg oil storafe Tribolium castaneum (Herbst) and Sitophilus zeamais Motsh. J. Stored Entomol, v.92, p.289-298, 1997.

JANTAN, I.B.; AHMAD, A.R.; AHMAD, A.S. et al. A comparative study of the essential oils of five Piper species from Peninsular Malasya. Flav. Frag. J., v.9, p.339-342, 1994.

JAYASEKARA, K.T.; STEVENSON，P. C.; BELMAIN, R.S. et al. Identification of methyl salicylate as the principal volatile component in the methanol extract of root bark of Securidaca longepedunculata Fers. J. Mass Spectr., v.37, 879-888, 2002.

LINDBERG, C.M.; MELATHOPOULOS, A.P.; WINSTON, M.L. Laboratory evaluation of miticides to control Varroa jacobsoni (Acari: Varroidae), a honey bee (Hymenoptera: Apidae) parasite. J. Econom. Entomol., v.93, p.189-198, 2000 .

MARANGA, R.O.; HASSANALI, A.; KAAYA, G.P. et al. Attraction of Amblyomma variegatum (ticks) to the attraction-aggregation-attachmentpheromone with or without carbon dioxide. Exp. Appl. Acarol., v.29, p.121-30, 2003.

MARTINS, A. P.; SALGUERO, L.; VILA, R. et al. Essential oils from four Piper species. Phytochemistry, v.49, p.2019-2023, 1998.

SCHONI, R.; HESS, E.; BLUM, W. et al. The aggregation-attachment pheromone of the tropical bont tick Amblyomma variegatum Fabricius (Acari, Ixodidae): Isolation, identification and action of its components. J. Insect Physiol., v.30, p.613-618, 1984.

SEIFERT, G.W.; SPRINGELL, P.H.; TATCHELL, R.J. Radioactive studies on the feeding of larvae, nymphs and adults of the cattle tick Boophilus microplus (Canestrini). Parasitology, v.58, p. 415-430, 1968.

SESKAR, M.; SHULAEV, V.; RASKIN, I. Endogenous methyl salicylate in pathogen- inoculated tobacco plants. Plant Physiol., v.116, p.387-392, 1998.

SHAAYA, E.; HOSTJUKOVSKI, M.; EILBERG, J. et al. Plant oils as fumigants and contacts insecticides for the control as storedproduct insects. J. Stored Prod. Res., v.33, p.715, 1997.

SINGH, D.; SINGH, A.K. Repellent and insecticidal properties of essential oils against housefly, Musca domestica L. insect. Sci. Appl., v.12, p.487-491, 1991.

SING, G.; UPADHAYAY, R.K. Essential oils: a potent source of natural pesticides. J. Sci. Ind. Res., v.52, p.676-683, 1993.

STUART, A.E.; BROOKS, C.J.W.; PRESCOTT, R.J. et al. Repellent and antifeedant activity of salicylic acid and related compounds against the biting midge, Culicoides impunctatus (Diptera: Ceratopogonidae). Entomol. Soc. Am., v.37, p.222-227, 2000.

SUTHERST, R.W.; MAYWALD, G.F.; KERR, J.D. et al. The effect of the cattle tick (Boophilus microplus) on the growth of Bos indicus $\mathrm{x}$ Bos taurus steers. Aust. J. Agric. Res., v.34, p.317$327,1983$.

TRABOULSI, A.F.; TAOUBI, K.; EL-HAJ, S. et al. Inseticidal properties of essential plants oils against the mosquito Culex pipiens molestus (Diptera: Culicidae). Pest Manag. Sci., v.58, p.491-495, 2002.

TUNC, I.; ERLER, F. Repellency and repellent stability of essential oil constituents against Tribolium confusum (Abstoßosende Wirkung der Komponenten von ätherischen Ölen auf Tribolium confusum und die Beständigkeit dieser Wirkung). Z. Pflanzenkr. Pflanzenschutz, v.110, p.394-400, 2003.

VERÍSSIMO, C.J.; PIGLIONE, R. Comportamento de larvas de carrapato diante de uma substância repelente. Arq. Inst. Biol., v.65, supl., p.75, 1998. 